UNIVERSIDADE

DO

PARANÁ
FACULDADE

DE

FILOSOFIA

REVISTA DOS CURSOS DE LETRAS

Diroforos: $\begin{aligned} & \text { R. F. MANSUR GUERIOS } \\ & \text { GUILLERMO DE LA CRUZ-CORONADO }\end{aligned}$

\begin{tabular}{llll}
\hline Curitiba - Brasil $\quad * * * \quad 1958 \quad$ N.0 \\
\hline
\end{tabular}

\title{
DUAS DÉCADAS VENCIDAS
}

O ano de 1958, ao marcar nos fastos universitários a instalação definitiva da Faculdade de Filosofia, Ciências e Letras da Universidade do Paraná em majestoso edifício que revela o poder realizador de uma equipe de homens de larga visão, assinalou também o decurso de vinte anos de existência da próspera instituição que marcha gloriosamente para grandes destinos no plano cultural.

Um pugilo de intelectuais, tendo à frente os eminentes Professôres Drs. Omar Gonçalves da Mota, Carlos de Paula Soares, de saudosa memória, e Homero de Melo Braga, que constituiam a Comissão Organizadora, reuniu-se ao 26 de fevereiro de 1938 para traçar as bases da entidade que, ao depois, seria uma das principais unidades universitárias quer pelas personalidades que reuniria em seu seio, quer pela profunda projeção que teria na órbita da cultura superior. Um Curso Complementar do antigo Ginásio Paranaense, a cargo do Estado, passaria a ser administrado pela novel instituição, nos moldes regimentais então elaborados, e constituiria fonte de renda para a manutenção da Faculdade.

Falhos tais recursos, como também os reduzidos meios de uma subvenção estadual, ocorreu a contingência de novos esforços salvadores sem os quais a iniciativa fracassaria ainda nos primórdios de sua vida institucional. Foi então que os 
Professôres P. Jesus Ballarin, da Congregação dos PP. Claretianos, e Dr. José Loureiro Fernandes, eminente cientista conterrâneo, aliaram seus esforços aos da plêiade inicial, atraíram novos elementos e puseram-se à frente de um movimento de reestruturação que encontrou decisivo apoio na União Brasileira de Educação e Ensino, constituída dos eméritos e infatigáveis Irmãos Maristas, notadamente da Província Central do Brasil, logrando assim dar novo alento ao grandioso plano realizador, quer pela acolhida da Faculdade em dependências do tradicional edificio do Colégio de Santa Maria, onde funcionou durante largos anos, quer pelo reconhecimento federal dos cursos de Filosofia, Ciências Sociais, Geografia e História, Ciências Químicas e Pedagogia, por Decreto n. 5.756 de 4 de junho de 1940

Seguiu-se o Decreto n. 6.411, de 30 de outubro de 1940, reconhecendo mais os Cursos de Matemática, Letras Clássicas, Letras Neolatinas e Letras Anglo-germânicas.

Designado Inspetor Federal junto ao estabelecimento o Dr. Gaspar Duarte Veloso, hoje senador da República, a Faculdade, que, no interregno da fase inicial até à reestruturação, funcionara precàriamente, do ponto de vista materiäl, em sedes provisórias, nos próprios da Assembléia Legislativa do Estado, em salas do Círculo de Estudos Bandeirantes, veio a ter, já sob a manutenção da União Brasileira de Educação e Ensino, inauguradas as dependências anexas ao Colégio de Santa Maria, à rua 15 de Novembro n..$^{\circ} 1004$, ocasião em que foi porta-voz da entidade mantenedora o virtuoso e revmo. Irmão Hipólito, tendo traduzido os sentimentos de gratidão da Faculdade de Filosofia o Prof. Dr. Homero de Melo Braga, como se vê da resenha histórica divulgada no Anuário de 1940-1941.

A Diretoria inicial fôra constituída dos Profs. Omar Gonçalves da Mota, diretor; Carlos de Paula Soares, vice-diretor e Homero de Melo Braga, secretário. E a primeira Diretoria, eleita a $1 .^{\circ}$ de agôsto de 1930, fôra integrada dos Profs. Dr. Brasil Pinheiro Machado, diretor; Revmo. P. Prof. Jesus Ballarin, C. M. F., vice-diretor, e Dr. Homero de Melo Braga, secretário. 
O quadro docente constava dos seguintes nomes: Catedráticos - Prof. P. Jesus Ballarin, Filosofia; Dr. Milton Carneiro, História da Filosofia; P. Jerônimo Mazzarotto, Psicologia; Dr. Omar Gonçalves da Mota, Sociologia; Desembargador Manoel Lacerda Pinto, Política; Dr. Valdemiro Teixeira de Freitas, Estatística Geral e Aplicada; Dr. José Bittencourt de Paula, Complementos de Matemática; Dr. Flávio Suplicy de Lacerda, Análise Matemática e Análise Superior; Dr. Algacyr Munhoz Maeder, Geometria Analítica; Dr. Conrado Erichsen, Mecânica Racional, Mecânica Celeste e Física Matemática; Dr. Arnaldo Isidoro Beckert, Física Geral e Experimental; Dr. Hipérides Zanello, Química Geral em inorgânica e Química Analítica; Dr. Francisco de Castro, Química Orgânica e Química Biológica; Dr. João Poeck, Físico- Química Superior; Dr. Homero de Melo Braga, Biologia Geral; Dr. Hans Ludwig Weber, Mineralogia e Petrografia; Dr. Francisco Villanueva, Geografia Física; Dr. José Nicolau dos Santos, Geografia Humana; Dr. Arthur Martins Franco, Geografia do Brasil; Dr. Homero Batista de Barros, História da Antiguidade e da Idade Média; Dr. José Farani Mansur Guérios, História Moderna e Contemporânea; Dr. Bento Munhoz da Rocha Neto, História da América; Dr. Brasil Pinheiro Machado, História do Brasil; Dr. José Loureiro Fernandes, Antropologia e Etnografia; Dr. Artur Ferreira dos Santos, Economia Política e História das Doutrinas Econômicas; Pe. João Batista Engler de Castro, Língua e Literatura Latina; P. José Gonzales Raposo, Língua e Literatura Grega; Dr. Rosário Farani Mansur Guérios, Língua Portuguêsa; Dr. Laertes de Macedo Munhoz, Literatura Portuguêsa; Dr. Temístocles Linhares, Literatura Brasileira; P. Eurípedes Olímpio de Oliveira e Sousa, Filologia Românica; Dr. Francisco Stobbia, Língua e Literatura Italiana; Pe. Felix Diaz de Zério, Língua e Literatura Espanhola; Frei Romualdo Hansaul, Língua Inglêsa e Literatura Inglêsa e Anglo-Americana; Dr. João Batista Doetzer, Língua e Literatura Alemã; Dr. Joaquim de Matos Barreto, Psicologia Educacional; Dr. Osvaldo Pilotto, Estatística Educacional; Dr. Francisco José Gomes Ribeiro, Administração Escolar e Educação Comparada; Dr. Liguarú Es- 
pírito Santo, História da Educação e Filosofia da Educação; Dr. Hostílio César de Sousa Araújo, Didática Geral. Assistentes: Dr. Orlando de Oliveira Melo, Psicologia Educacional: Dr. Ernesto Sigel Filho, Língua e Literatura Alemã; P. Artidório Aniceto de Lima, Iíngua e Literatura Latina; Dr. Máximo Pinheiro Lima, Antropologia; Prof. Nilo Brandão, Literatura Portuguêsa; Prof. Lauro Esmanhoto, Administração Escolar e Educação Comparada; Frof. Artoriges Zanello, Química Analítica Qualitativa e Quantitativa; Prof. Ernesto Ervino Drischel, Química Biológica; Prof. João José Vassão, Química Superior. Professores Contratados: Dr. Zbigniew Lepecki, Análise Matemática, e Prof. P. Augusto Fonseca, Língua e Literatura Francesa.

No decorrer dos anos, o quadro docente da Faculdade ressentiu-se de perdas de mestres eminentes, quer atingidos pela morte como José Farani Mansur Guérios, Pe. Jesus Ballarin, Carlos Paula Soares, Conrado Erichsen, Frei Romualdo Hansaul, João Batista Doetzer, além de outros que, posteriormente admitidos, tiveram igual destino como Arion Niepce da Silva, P. Augusto Fonseca, Osvaldo Pinheiro dos Reis, deixando claros de difícil preenchimento na luzida Congregação; quer chamados a outras ordens de atividades que os impossibilitaram de participar do labor quotidiano da Faculdade, como Orlando de Oliveira Melo, Nilo Brandão, João José Vassão, Ernesto Ervino Drischel, sem falar dos catedráticos, dentre os quais um dos fundadores, Prof. Omar Gonçalves da Mota, P. Jerônimo Mazzarotto, hoje preeminente antístite, Prof. Flávio Suplicy de Lacerda, atual Reitor Magnífico, Prof. Hipérides Zanelo, Prof. Francisco Villanueva, Prof. Arthur Martins Franco, Prof. Arthur Ferreira dos Santos, Prof. Laertes Munhoz, Prof. Joaquim de Matos Barreto e outros nomes não menos eminentes.

Da Diretoria participaram, sucessivamente, os Profs. Omar Gonçalves da Mota, Brasil Pinheiro Machado, Desemb. Manoel Lacerda Pinto, José Loureiro Fernandes e Homero Batista de Barros, todos empenhados, com altos propósitos, em levar a bom têrmo os graves encargos que a Congregação e o Govêrno da República, ao designá-los, houveram por bem confiar-lhes. 
Capíttulo que se perpetuará nos anais universitários é sem dúvida o da vida estudantil da Faculdade de Filosofia, onde as gerações que, nas duas décadas, se sucederam assinalaram um novo estilo de vida acadêmica, notadamente do ponto de vista social, pois que, enquanto nas demais unidades universitárias do Paraná preponderam as turmas de rapazes, na Faculdade de Filosofia se faz distinto o elemento feminino, representativo de tradicionais famílias paranaenses, no borborinho diário das aulas. A par dessa mocidade que sabe reunir a graça à inteligência, os estudantes, tão bem representados no Centro Acadêmico de Filosofia e no Diretório Acadêmico de Filosofia, constituem uma falange vigilante dos interêsses universitários, sempre à frente das causas nobres que têm reclamado tomada de posição.

A vida cultural da escola, assim no campo das ciências especulativas como em o das positivas, é a mais intensa e promissora. Pesquisas, conferências, cursos de extensão cultural, excursões de estudos e demais iniciativas, ao lado de publicações, teses e concursos, revelam excelente índice de prosperidade e de florescimento em largas perspectivas.

Com vinte anos de existência, patrocínio dos poderes públicos federais e instalações moderníssimas, a Faculdade de Filosofia da Universidade do Paraná já constitui uma vitória de que todos nos podemos orgulhar, tanto mais quanto volvermos as vistas para um esperançoso porvir. 